Provided by the author(s) and University of Galway in accordance with publisher policies. Please cite the published version when available.

\begin{tabular}{|c|l|}
\hline Title & $\begin{array}{l}\text { Framing or gaming? Constructing a study to explore the impact } \\
\text { of option presentation on consumers }\end{array}$ \\
\hline Author(s) & Barry, Chris; Hogan, Mairéad; Torres, Ann \\
\hline $\begin{array}{c}\text { Publication } \\
\text { Date }\end{array}$ & 2016-02-18 \\
\hline $\begin{array}{c}\text { Publication } \\
\text { Information }\end{array}$ & $\begin{array}{l}\text { Barry, Chris, Hogan, Mairead, \& Torres, Ann. (2015). Framing } \\
\text { or gaming? Constructing a study to explore the impact of } \\
\text { option prentation on consumers. Paper presented at the 24th } \\
\text { International conference on information systems development, } \\
\text { Harbin. }\end{array}$ \\
\hline $\begin{array}{c}\text { Link to } \\
\text { publisher's } \\
\text { version }\end{array}$ & $\begin{array}{l}\text { http://aisel.aisnet.org/isd2014/proceedings2015/ISDevelopment } \\
/ 2\end{array}$ \\
\hline $\begin{array}{c}\text { Item record } \\
\text { Dol }\end{array}$ & http://hdl.handle.net/10379/5570 \\
\hline htt//dx.doi.org/10.13025/S8H598
\end{tabular}

Downloaded 2023-04-26T02:30:19Z

Some rights reserved. For more information, please see the item record link above.

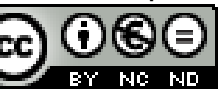




\title{
Framing or Gaming? Constructing a Study to Explore the Impact of Option Presentation on Consumers
}

Chris Barry

National University of Ireland Galway Galway, Ireland

Mairéad Hogan

National University of Ireland Galway Galway, Ireland

Ann M. Torres

National University of Ireland Galway

Galway, Ireland chris.barry@nuigalway.ie

mairead.hogan@nuigalway.ie

ann.torres@nuigalway.ie

\begin{abstract}
The manner in which choice is framed influences individuals' decision-making. This research examines the impact of different decision constructs on decision-making by focusing on the more problematic decision constructs: the un-selected and pre-selected optout. The study employs eye-tracking with cued retrospective think-aloud (RTA) to combine quantitative and qualitative data. Eye-tracking will determine how long a user focuses on a decision construct before taking action. Cued RTA where the user will be shown a playback of their interaction will be used to explore their attitudes towards a decision construct and identify problematic designs. This pilot begins the second of a three phase study, which ultimately aims to develop a research model containing the theoretical constructs along with hypothesized causal associations between the constructs to reveal the impact of measures such as decision construct type, default value type and question framing have on the perceived value of the website and loyalty intentions.
\end{abstract}

Keywords: Framing of choice, decision constructs, consumer involvement, elaboration likelihood model, optionality presentation, opt-out, must-opt, eye-tracking.

\section{Introduction}

This paper continues a stream of research conducted by the authors over recent years into questionable practices in the low-cost carrier (LCC) sector in Ireland and Europe. From a number of studies it was established that experts in web design and representative users found their experience to be highly problematic in fully understanding flight prices, taxes and charges, avoiding optional extras and navigating a stress-free path to a commercial conclusion. The authors found some decisions were presented to users utilizing highly unorthodox decision constructs. From here, and before conducting further planned research, a study was conducted to fully identify and compose a taxonomy of all types of decision constructs presented to users in the business-to-consumer (B2C) commercial transactional process. This paper traces the journey and lays out the formulation of a pilot study to measure how decision construct design impacts on how long it takes users to complete specific tasks. Thereafter follow several research phases to develop a framework that will enhance practitioners' and researchers' understanding of the impact of option presentation on the decision-making of consumers during the transactional process in $\mathrm{B} 2 \mathrm{C}$ interactions. 


\section{Decision Framing and Gaming}

\subsection{Research on Option or Choice Framing}

The framing of choice for decision-making has been the subject of research in many disciplines over the past forty years. From early classical economics, the way alternative choices were presented to decision-makers was thought not to affect an individual's capacity to rank them, assign probabilities to outcomes, and select the one with the highest utility. This rational choice model assumes an objective individual who rationally makes optimal decisions. Hence, given the same data, rational individuals would always make the same decision.

The theory of rational choice, governing social and economic behaviour, has been questioned across a number of disciplines. Simon [31] was among the first to signal its limitations by proposing the concept of 'bounded rationality'. Subsequently, Tversky and Kahneman [37] theorised framed information could be encoded positively or negatively. Their research indicated the manner in which choice is framed to individuals significantly influences decision-making. They concluded the dependence of preferences on the formulation of decision problems constitutes a major concern for the theory of rational choice.

In real-world cases, Samuelson and Zeckhauser [30] found decisions are often presented with 'influential labels', whereby there is nearly always one alternative that carries the label 'status quo'. In a series of experiments designed to test for status quo effects, they concluded decision-makers exhibited a significant choice bias towards the status quo. Similarly, though in varied contexts, other studies [3] [20] [22] conclude individuals are more likely to retain a default option than to change it, even if the decision is detrimental to them. Hence, users were more likely to participate if an option is presented as an opt-out, rather than an opt-in; the reasons for which vary from: trust in a default; a presumption that it is a recommendation; and participant inertia.

Bellman et al. [3] explored the impact of question framing on user decisions. In querying how consumers have unknowingly opted-in to something, they explored the tactics some firms employ to encourage consent. They identified different ways in which consent can be obtained and concluded there are consequential effects in how questions are presented to consumers. Indeed, by using the correct combination of question framing and default answers, firms 'can almost guarantee' consent. Lai and Hui [22] also conducted research into the impact of question framing on user decisions. Their study indicates the manner in which the option is described, as well as the default option (i.e., checked or unchecked), has an impact on user choice. They found for opt-in decisions using checkboxes, users are more likely to accept an un-selected opt-in over a pre-selected opt-in. They suggest the positive language of acceptance is likely to influence the users' decision.

\subsection{Gaming}

The challenges consumers experience with online decision-making is best evidenced through the LCC industry, as it developed over the last two decades. Some carriers, such as Ryanair, promoted a brash and belligerent image to reflect that passengers were buying cheap flights and that customer service was a casualty of this Faustian pact [34.]

For some LCCs, many non-sales related activities are simply removed or distanced from consumers. This deconstructed, no-frills business model is often reflected in the design of the supporting web-based information system. Conventionally, information systems seek to provide an engaging end-user experience that encourages repeat business and customer retention. However, there remains a gap between the functionality one would expect to find in sophisticated, web-based information systems and what LCCs actually offer. The route to purchase, once users pass a committal point, degenerates into an adversarial transactional process that involves consumers navigating as many as a dozen optional extras that are variously opt-in, opt-out, must-opts (see Table 1) and sometimes, 
repeated 'offers' suggesting consumers have not made the correct decision in rejecting the option. This practice is effectively gaming. A forgiving interpretation is that the cheap flights are enhanced by optional, ancillary charges. A more cynical interpretation is that the flight price is deconstructed into an apparent cheap headline price, but reconstructed into a much greater price via a plethora of unavoidable taxes and charges, and an array of optional charges, some of which are made difficult to avoid and are unorthodox in their design.

Due to practices by a significant number of European airlines, the European Union legally require optional extras on airline websites only be presented to consumers on an optin basis [10] [11]. However, Barry, Hogan and Torres [2], found some Irish airlines were using an unconventional design pattern to present optional extras that forced consumers to make a choice, rather than progress un-hindered. This construct, termed a 'must-opt', required users to accept or reject the item before continuing with the interaction. The study examined user perceptions of the level of compliance of two airlines with the relevant European Union legislation and found users were significantly frustrated by a long series of optional extras presented in an unorthodox manner. Neither did they believe the airlines to be compliant with the European Union requirement to communicate all optional extras in a clear, transparent and unambiguous manner. From this research, the authors went on to produce an exhaustive taxonomy of decision constructs (see Table 1) used in B2C transactional processes [35]. In testing the taxonomy, certain constructs were found to be problematic, particularly opt-outs and must-opts, in respect of the clarity of the optionality and the level of opacity [15].

The research and discussion above and in Section 2.1 establishes the framing and gaming of choice and the presentation of defaults have a significant impact and influence on user decision-making.

Table 1. A taxonomy of decision constructs in $\mathrm{B} 2 \mathrm{C}$ transactions.

\begin{tabular}{|c|c|}
\hline Decision Construct & Description \\
\hline Un-selected opt-in & $\begin{array}{l}\text { This decision construct has a default option of not receiving the option. It } \\
\text { is generally presented as an un-ticked check box or a radio button set to } \\
\text { off, where the option is framed in an acceptance format. Thus, the } \\
\text { terminology states the customer wants the option. }\end{array}$ \\
\hline Pre-selected opt-in & $\begin{array}{l}\text { This decision construct has a default option of not receiving the option. It } \\
\text { is generally presented as a ticked check box or a radio button set to on, } \\
\text { where the option is framed in a rejection format. Thus, the terminology } \\
\text { states the customer does not want the option. }\end{array}$ \\
\hline Un-selected opt-out & $\begin{array}{l}\text { This decision construct has a default option of receiving the option. It is } \\
\text { generally presented as an un-ticked check box or a radio button set to off, } \\
\text { where the option is framed in a rejection format. Thus, the terminology } \\
\text { states the customer does not want the option. }\end{array}$ \\
\hline Pre-selected opt-out & $\begin{array}{l}\text { This decision construct has a default option of receiving the option. It is } \\
\text { generally presented as a ticked check box or a radio button set to on, } \\
\text { where the option is framed in an acceptance format. Thus, the } \\
\text { terminology states the customer wants the option. }\end{array}$ \\
\hline Must-opt & $\begin{array}{l}\text { A must-opt decision occurs when an optional extra is presented to a } \\
\text { customer as un-selected. It is not possible to proceed to the next webpage } \\
\text { without having made a selection. It is generally presented as radio } \\
\text { buttons, command buttons or a drop down list. }\end{array}$ \\
\hline $\begin{array}{l}\text { Un-selected essential } \\
\text { decision }\end{array}$ & $\begin{array}{l}\text { An un-selected essential decision is where none of the variants has been } \\
\text { pre-selected for the customer. Unlike the must-opt, this construct does } \\
\text { not offer an optional extra as the user must choose one of the presented } \\
\text { variants. For example, the customer chooses a payment method. }\end{array}$ \\
\hline $\begin{array}{l}\text { Pre-selected } \\
\text { essential decision }\end{array}$ & $\begin{array}{l}\text { A pre-selected essential decision is where one of the variants has been } \\
\text { pre-selected for the customer. Unlike the must-opt, this construct does } \\
\text { not offer an optional extra as the user must choose one of the presented } \\
\text { variants. It may be in either the customer's or the vendor's favour, or it } \\
\text { may be neutral. For example, fast delivery for a surcharge may be pre- } \\
\text { selected. }\end{array}$ \\
\hline
\end{tabular}




\subsection{Involvement and the Elaboration Likelihood Model}

Consumer decisions fall along a continuum of limited to extensive decision-making and it is the degree of consumer involvement that largely determines the type of decision-making [29]. Involvement reflects the amount of time and effort an individual invests in the decision-making process and is typically separated into two levels - high and low involvement. Therefore, high involvement (i.e., extensive decision-making) signals the individual cares about the decision and/or it is meaningful to them, whereas low involvement signals the opposite.

Involvement is defined as an individual's internal state, which reflects their level of arousal or interest in an object [6]. Involvement's stability makes it a key determinant of consumer behaviour, as it is resistant to external influences [33]. Highly involved individuals use a more systematic process for decision-making [36]. Consequently, they exert considerable effort in searching and examining information, and carefully elaborate their beliefs with respect to a specific object [14]. In contrast, less involved individuals exhibit the opposite behaviour by spending less time and engaging in fewer information seeking behaviours [24].

Relating involvement to the elaboration likelihood model (ELM), the same information can be processed in different ways, depending on the individual's level of involvement [27]. For example, individuals who are motivated (i.e., highly involved) are more likely to process a message via the central route [23]. That is, they are likely to engage in thoughtful consideration of the message and incorporate their own assessment of the arguments. Furthermore, meta-analytic research indicates that as involvement increases, so does the importance of argument quality [19].

In contrast, individuals who are unmotivated (i.e., less involved) are more likely to process a message via the peripheral routes, which represent mental shortcuts that focus on non-content cues [4]. Hence, when involvement is low, individuals are more likely to rely on peripheral cues from the stimulus (i.e., the firm). Thus, less involved consumers may simply accept what a firm recommends because they have low motivation to process content information, a similar phenomenon found in studies mentioned earlier [3] [20] [22].

Applying the ELM, one would expect individuals who spend a considerable amount of time on a decision construct are highly involved, while individuals who spend a limited amount of time on the same decision construct are less involved. The question is whether certain decision constructs (e.g., opt-outs) have the same results as those predicted with ELM. To date, no study has specifically investigated the effects of decision construct characteristics and the moderating effect of user involvement on purchasing intention. This perspective will be examined as part of the proposed research plan.

\section{Deconstructing Options}

\subsection{Dimensions of Option Presentation}

The presentation of options to consumers in contemporary B2C interactions is made up of a number of dimensions. Much of the research discussed earlier on framing largely related to a singular dimension, that of a polar decision, choosing one of two options. In the more sophisticated world of online consumerism, the presentation of choice and optionality can be greatly finessed. The presentation of an option may now have multiple, even layered, dimensions.

Previous research [15] [35] determined options tend to be presented to the user in a variety of ways. Some options are straightforward with easy to understand defaults and choices, while other options are more complicated and require effort to decipher so as to identify the default and the action required to achieve the desired outcome. In addition, some options are simply presented to the consumer while others incorporate various levels of persuasion, presumably to encourage selection of the vendor's preferred outcome. The less straightforward decision constructs encountered were pre-selected and un-selected opt- 
outs, must-opts and pre-selected opt-ins. This initial stage of research examines pre-selected and un-selected opt-outs while later stages will examine the other decision construct types.

A desk analysis of 57 websites was conducted to determine the fundamental dimensions of option presentation for opt-out decision constructs in use in B2C websites. A total of 42 opt-outs were encountered across 17 of the websites examined. A number of dimensions were identified as contributing to option presentation, namely:

- control type (e.g., check box, radio button, drop-down menu);

- default value (i.e., un-selected or pre-selected);

- question or information framing (i.e., acceptance, rejection or neutral language);

- general purpose of the construct (e.g., immediate revenue generation, permission to collect or retain personal data, permission to contact the consumer regarding this purchase); and

- additional persuaders (e.g., benefits of choosing the option, risks of rejecting the option, reassurance of privacy).

From these, the fundamental dimensions of option presentation were distilled as: default value; framing; and additional persuaders. The default value is either pre-selected or un-selected. For example, a pre-selected checkbox would be pre-ticked, while an unselected checkbox would not be ticked. The framing deals with the way in which the question or text associated with the decision construct is presented, and can be acceptance (e.g., Please send me the newsletter), rejection (e.g., I do not want travel insurance) or neutral, where the option is simply stated (e.g., Newsletter). The third component of option presentation is the use of additional persuaders. The additional persuader can vary in level of persuasion from a brief statement of benefits to much more comprehensive persuaders including details on the risks associated with declining the option, extensive statement of benefits and reassurance regarding protection of privacy, security or the ability to reverse the decision if desired. The dimensions of option presentation are outlined in Table 2 .

Table 2. Dimensions of option presentation.

\begin{tabular}{|l|l|}
\hline Dimension & Presentation \\
\hline Default Value & Pre-selected or Un-selected \\
\hline Question/Information Framing & Acceptance, Rejection or Neutral \\
\hline Additional Persuaders & Yes or No \\
\hline
\end{tabular}

\subsection{Exploring Opt-out Options}

Once the dimensions of option presentation were identified, the opt-outs were examined to determine how they fit in to the structure of default value, question/information framing and additional persuaders (see Table 2). Of the 42 opt-outs encountered, 36 were pre-selected and 6 were un-selected. Of the 36 pre-selected opt-outs, 26 used acceptance framing, 1 used rejection framing and 9 used neutral framing. In all cases, this neutral framing was deemed to have an acceptance slant, as the option was pre-selected. All the un-selected opt-outs used rejection framing. 


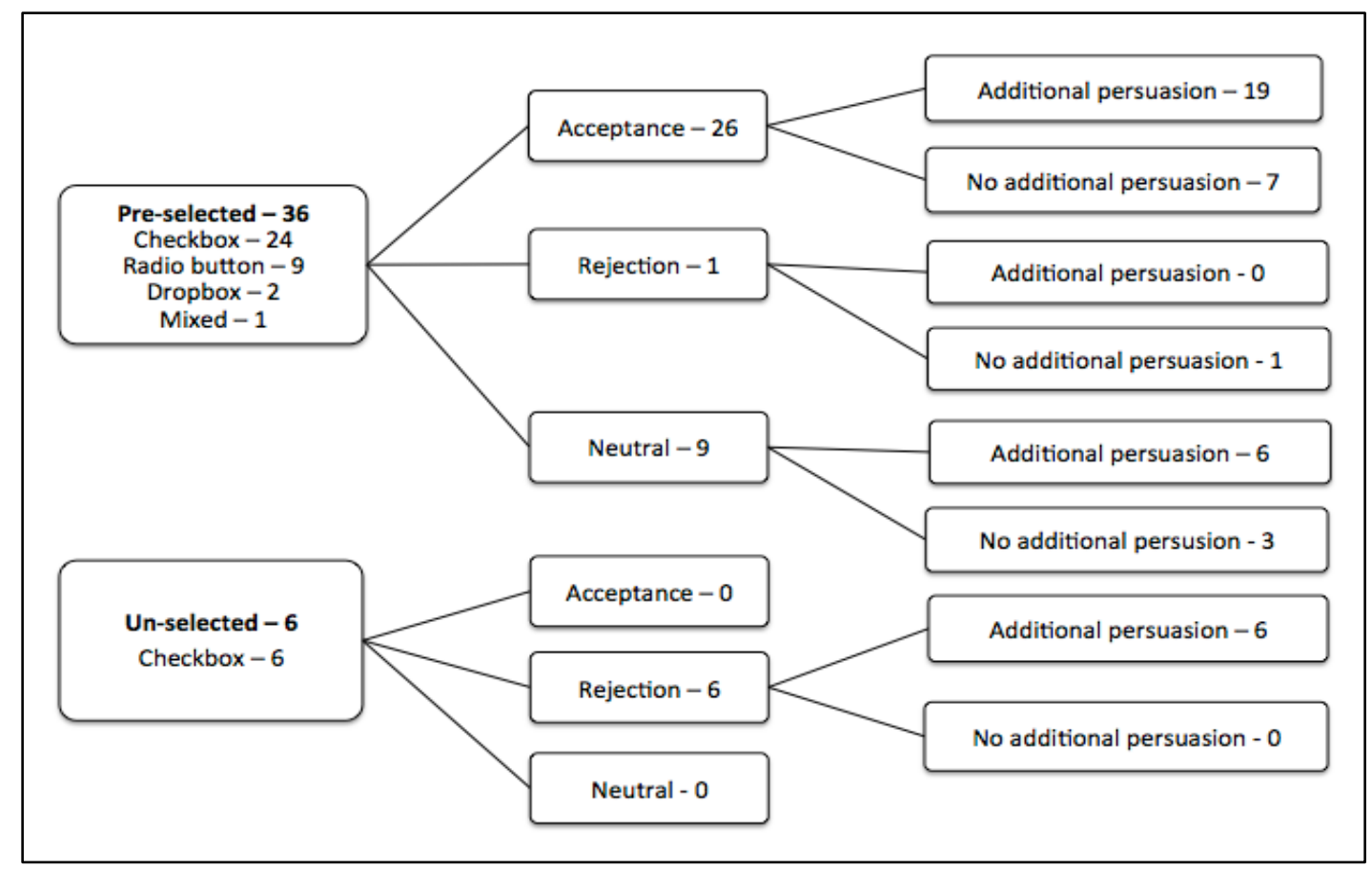

Fig. 1. Desk analysis of option presentation in practice - opt-outs.

The use of additional persuaders included in the decision constructs varied. Of the 26 pre-selected opt-outs that used acceptance framing, 19 used additional persuaders, including brief or extensive description of the benefits, enthusiastic language, reassurance of credibility, and detailing of the risks of declining the option. The remaining 7 used no additional persuaders. The one pre-selected opt-out using rejection framing used no additional persuaders while 6 of the 9 using neutral framing used additional persuaders and the remaining 3 did not. All 6 of the un-selected opt-outs used additional persuaders. Figure 1 summarizes these desk analysis findings.

Table 3. Levels of persuasion.

\begin{tabular}{|l|l|}
\hline Persuasion Level & Examples \\
\hline Weak & $\begin{array}{l}\text { "Send me offers and promotions from ... " } \\
\text { "Please send special offers" }\end{array}$ \\
\hline Moderate & "Sign me up! I'd like to receive promotional material from ..." \\
\hline Strong: & "What if I need to cancel? \\
Multiple approaches to & $\begin{array}{l}\text { We understand. So, we 're proud to offer cancellation insurance } \\
\text { just in case [...] box offices don't ever allow refunds or } \\
\text { exchanges, but since we're aware that bad weather, family } \\
\text { emergencies and the like can arise that may prevent you from } \\
\text { attending a show as planned you can get it from us for an } \\
\text { additional \$20.00 per ticket. } \\
\text { Then we'll give you a full refund of the ticket cost (less the } \\
\text { insurance and service fees), as long as we receive your tickets in } \\
\text { our office at least two business days prior to the performance. } \\
\text { Sound good?" }\end{array}$ \\
\hline $\begin{array}{l}\text { Strong: } \\
\text { opw risk in accepting } \\
\text { option }\end{array}$ & $\begin{array}{l}\text { Privacy \& Promotional Offers } \\
\text { The privacy of our guests is our utmost concern. We will never } \\
\text { sell or distribute your information. If you would like to receive } \\
\text { special offers we promise to never send more than } 1 \text { email per } \\
\text { month. }\end{array}$ \\
\hline
\end{tabular}


The additional persuaders used with the opt-outs varied considerably in strength and are categorized as: none, weak, moderate or strong. A brief description of benefits was considered to be a persuader due to the positive connotations and desirability associated with terms like 'promotions' and 'special offers'. However, they would be considered weak persuaders, as they do not include extensive descriptions of the benefits (see Table 3). Moderate persuaders have more extensive detail about the benefits, or use more enthusiastic language. The use of the bold text and the exclamation mark in the example in Table 3 , coupled with the positive connotations associated with the term 'promotional material' would be likely to emphasize the desirability of this option.

Strong persuaders use multiple approaches to encourage the user to accept the vendor's preferred decision. Multiple examples of strong persuaders were encountered across a variety of websites. In some cases the benefits of purchase were combined with the risks of rejection. In others, the consumer was reassured that their data would be protected in addition to describing the benefits of purchase.

An example of a strong persuader was encountered when the option of cancellation insurance was presented to the consumer in the process of purchasing tickets (see Table 3). This particular example describes the risks of rejecting the option (i.e., not being able to get a refund), as well as describing the benefits of purchase (i.e., getting a refund if the consumer is unable to attend the show). It further persuades by the description of common events (e.g., bad weather) that may force the consumer to cancel and thus, reinforces the importance of purchasing insurance. Another example seeks to reassure the consumer there is little risk associated with the acceptance of the option (see Table 3). In addition to the use of the term 'special offers', which has positive connotations, this example also seeks to reassure the consumer their data will be protected and they will not receive an excessive volume of e-mails, thus minimizing the potential risks often associated with mailing lists.

\section{Exploratory Study}

\subsection{Background to Eye Tracking Research}

Modern eye-tracking technology works on the principle of focusing a light and a video camera on a person's eye to determine where the individual is looking on screen [26]. When an individual wants to pay attention to something, they fix their gaze on it and it comes into sharp focus. This focus is referred to as a fixation. A person typically moves their eye across various items of interest. These movements, referred to as saccades, are jerky and happen so quickly, we are not aware of them. The saccades are rapid, lasting between onehundredth and one-tenth of a second, while fixations last between one-tenth and a half second [26].

Eye-tracking has been used extensively in web usability studies [9] [7] [17] [32] [8]. Goh et al. [13] compared a number of usability testing techniques for an e-commerce website and found the use of retrospective think-aloud with eye movement (RTE) identified significantly more usability problems than retrospective think-aloud (RTA), observation or feedback capture after task (FCAT).

By studying what users do and do not look at, it is possible to determine where they are concentrating their attention [28]. Through the examination of eye movement patterns, conclusions may then be drawn on the decision-making strategies users adopt [12] [17] [5].

\subsection{Research Plan and Approach}

The research plan involves three phases [15] and is summarised in Table 4. Firstly, to identify an exhaustive list of the various decision constructs encountered when purchasing a product or service whilst on-line and then to consider some of the more salient issues that surround the transactional process. This phase, as discussed earlier, has already been 
conducted. Secondly, a more intense analysis, made up of two parts, of the presentation of the decision constructs, including an exploration of the juxtaposition between optionality and question framing will be conducted. Eye-tracking and cued RTA will be used as research techniques. Thirdly, a research model, broadly based on the E-S-QUAL research instrument, will be composed containing the theoretical constructs (such as service quality, social value, perceived value of website, loyalty intentions and increased peer recommendation) along with hypothesized causal associations between the constructs. Measures, unique to the study, will be validated. These will include industry category, decision construct type, default value type, persuasion and question framing.

This pilot study seeks to address the initial aspect of the second phase of the research plan outlined above. Its purpose is to determine the impact of different decision constructs on decision-making. The focus is on two of the more problematic decision constructs, namely the un-selected and pre-selected opt-out [35]. From the first phase findings, the following key research question emerged: RQ: How are users impacted by differently designed opt-out decision constructs?

There are two steps in both parts of the second phase of the research plan:

1) An eye-tracking study where the user's gaze is tracked while completing a simple task using two types of decision constructs ${ }_{2}$ a pre-selected opt-out and an un-selected optout. Different presentation options will be used for both pre-selected and un-selected optouts (see Table 2). These formats will be based on typical presentation options encountered during the desk analysis described in Section 3 and will include pre-selected and unselected opt-outs. There will be variants of these using different types of framing, both with and without different levels of persuaders (see Table 3). The data gathered includes the user's pattern of eye movement, as well as tracking how long a user focuses on a particular part of the screen. These data allow the researchers to determine how long a user focuses on each of the decision constructs before taking action.

2) Cued retrospective think-aloud sessions where the user talks about the task just completed. The user describes the thought process followed during the task, providing rich, contemporaneous, qualitative data to enhance the quantitative data obtained from eyetracking. It is important the eye-tracking data is supplemented with additional qualitative data [18], as eye movements simply show the eye movement pattern with no information on why a user is fixating on a particular part of the screen. For example, a long fixation could be due to either interest or difficulty understanding the information.

There are two think-aloud approaches: concurrent think-aloud (CTA), where an end user thinks out loud while carrying out tasks on a system, and retrospective think-aloud (RTA), where the user provides a description of their thought processes after the tasks have been completed [18]. This verbalization helps the evaluator to understand the user's attitudes towards the system and to identify aspects of the design that are problematic for the user [16]. The sessions are taped and a separate scribe may also take detailed notes of the comments and actions of the user [25]. For this study, CTA was not considered to be an appropriate approach, as it can bias the user's first impression and may influence their visual fixations [21]. RTA also has potential problems, as the user is relying on memory to describe their cognitive processes and may forget information or attempt to justify their actions, leading to erroneous data [1]. However, the use of cued RTA, where the user is shown a playback of their interaction has been found to be more effective at eliciting comments than un-cued RTA [1]. While van den Haak et al. [38] found RTA and CTA identified comparable numbers of usability problems, combining eye-tracking with cued RTA allows the researcher to effectively combine quantitative eye-tracking and qualitative RTA data.

Pernice and Nielsen [28] recommend six users for qualitative eye-tracking (i.e., watching gaze replays). As this pilot is testing the approach before conducting a larger scale study, six users will carry out the tasks while their gaze is tracked using the eye-tracking equipment. They will be shown a replay of their interaction with the gaze pattern superimposed on the screen. While watching the replay, they will describe why they made their decisions and what they were thinking while interacting with the decision constructs. 
The tasks presented to the users will involve making certain selections using a variety of opt-out decision constructs. These constructs will be both pre-selected and un-selected with the associated information presented in a variety of ways.

Table 4. Research Plan.

\begin{tabular}{|c|c|c|}
\hline Phase & Description / Objective & Output \\
\hline Phase 1 & $\begin{array}{l}\text { To identify an exhaustive list of } \\
\text { decision constructs encountered } \\
\text { in the B2C transactional } \\
\text { process. Some of the more } \\
\text { salient issues that surround the } \\
\text { transactional process were } \\
\text { examined in an exploratory } \\
\text { analysis of } 77 \text { decision } \\
\text { constructs from } 15 \text { websites } \\
\text { across } 5 \text { sectors [15]. }\end{array}$ & $\begin{array}{l}\text { An exhaustive mutually } \\
\text { exclusive taxonomy of all } \\
\text { decision constructs the B2C in } \\
\text { transactional process was } \\
\text { constructed (see Table } 1 \text { ). }\end{array}$ \\
\hline Phase 2 - Part 1 & $\begin{array}{l}\text { A pilot study, the subject of this } \\
\text { paper, will be conducted to } \\
\text { examine the impact of different } \\
\text { decision constructs on decision- } \\
\text { making, by focusing on the un- } \\
\text { selected and pre-selected opt- } \\
\text { out }\end{array}$ & $\begin{array}{l}\text { It is expected the research } \\
\text { output will validate the } \\
\text { research design for Phase } 2 \text {. }\end{array}$ \\
\hline Phase 2 - Part 2 & $\begin{array}{l}\text { The results from Part } 1 \text { will } \\
\text { inform an extensive eye- } \\
\text { tracking and cued RTA study to } \\
\text { comprehensively analyse all of } \\
\text { the constructs within the } \\
\text { taxonomy. }\end{array}$ & $\begin{array}{l}\text { The expected outcome will } \\
\text { confirm the key dimensions } \\
\text { influencing decision-making } \\
\text { and an understanding of user's } \\
\text { involvement, rationale and } \\
\text { thought processes. }\end{array}$ \\
\hline Phase 3 & $\begin{array}{l}\text { Finally, a research model will } \\
\text { be developed to determine the } \\
\text { causal relationship between the } \\
\text { key factors such as user } \\
\text { involvement, efficiency, level } \\
\text { of persuasion and trust. }\end{array}$ & $\begin{array}{l}\text { The research model will } \\
\text { demonstrate how the theoretica } \\
\text { constructs are positively or } \\
\text { negatively impacted by other } \\
\text { factors. }\end{array}$ \\
\hline
\end{tabular}

\section{Summary of Research Plan}

This paper describes a desk analysis conducted to inform the design for a more comprehensive study gauging the time users spend in examining different types of decision constructs. In addition, the study will explore the rationale and the thought processes in making a decision when users are presented with various types of decision constructs. An in-depth pilot will ensure the study is designed to adequately address the research question. The way in which the decision constructs are presented will be considered, as will issues associated with the cued RTA and eye-tracking itself. The participants will be questioned regarding these issues and others arising during the pilot study.

Once the pilot is complete, a larger study that examines all the previously identified decision constructs will be conducted. It will involve a greater number of participants and will include all decision constructs identified within the taxonomy previously described. This comprehensive study completes phase two of the research plan discussed in Section 4.2. 
The third phase of the research plan involves composing a research model containing the theoretical constructs along with hypothesized causal associations between the constructs. This study will enhance practitioners' and researchers' understanding of the impact of decision construct presentation on users' decision-making during the transactional process in $\mathrm{B} 2 \mathrm{C}$ interactions.

\section{References}

[1] Ball, L.J., Eger, N., Stevens, R., and Dodd, J. 2006. "Applying the PEEP Method in Usability Testing," Interfaces (67), pp. 15-19.

[2] Barry, C., Hogan, M. and Torres, A. 2011. "Perceptions of Low Cost Carriers' Compliance with EU Legislation on Optional Extras," in 20th International Conference on Information Systems Development, August 24-26, Edinburgh, Scotland.

[3] Belman, S., Johnson, E., and Lohse, G. 2001. "To Opt-In or Opt-Out? It Depends on the Question," Communications of the ACM (44:2), pp. 25-27.

[4] Celsi, R.L., and Olson, J.C. 1988. "The Role of Involvement in Attention and Comprehension Processes," Journal of Consumer Research (15:2), pp. 210-224.

[5] Day, R., Shyi, G., and Wang, J. 2006. "The Effect of Flash Barriers on Multiattribute Decision Making: Distractor or Source of Arousal?," Psychology \& Marketing (23:5), pp. 369-382.

[6] Dholakia, U.M. 2001. "A Motivational Process Model of Product Involvement and Consumer Risk Perception,” European Journal of Marketing (35:11/12), pp. 13401360.

[7] Di Stasi, L., Antoli, A., Gea, M., and Canas, J. 2011. "A Neuroergonomic Approach to Evaluating Mental Workload in Hypermedia Interactions," International Journal of Industrial Ergonomics (41), pp. 298-304.

[8] Djamasbi, S., Siegel, M., Tullis, T., and Dai, R. 2010. "Efficiency, Trust, and Visual Appeal: Usability Testing Through Eye Tracking," in the 43rd Hawaii International Conference on System Sciences (HICSS), pp. 1-10. IEEE.

[9] Djamasbi, S., Siegel, M., Skorinko, J., and Tullis, T. 2011. "Online Viewing and Aesthetic Preferences of Generation Y and the Baby Boom Generation: Testing User Web Site Experience Through Eye Tracking. International Journal of Electronic Commerce (15:4), pp. 121-158.

[10] European Union. 2008. 1008/2008, Regulation of the European Parliament and of the Council on Common rules for the Operation of Air Services in the Community (recast).

[11] European Union. 2011. 2011/83/EU, Directive on Consumer Rights.

[12] Glöckner, A. and Herbold, A.K. 2011. "An Eye-tracking Study on Information Processing in Risky Decisions: Evidence for Compensatory Strategies Based on Automatic Processes," Journal of Behavioral Decision Making (24), pp. 71-98.

[13] Goh, K.N., Chen, Y.Y., Lai, F.W., Daud, S.C., Sivaji, A., and Soo, S.T. 2013. "A Comparison of Usability Testing Methods for an E-Commerce Website: A Case Study on a Malaysia Online Gift Shop," in the Tenth International Conference on Information Technology: New Generations (ITNG), pp. 143-150. IEEE.

[14] Herrero, A, and San Martín, H. 2012. "Effects of the Risk Sources and User Involvement on e-Commerce Adoption: Application to Tourist Services," Journal of Risk Research (15:7), pp. 841-855.

[15] Hogan, M., Barry, C., and Torres, A. 2014. "Theorising and Testing a Taxonomy of Decision Constructs," Journal of Customer Behaviour (13:3), pp. 181-186.

[16] Holzinger, A. 2005. "Usability Engineering Methods for Software Developers," Communications of the ACM (48:1), pp. 71-74.

[17] Huang, Y. and Kuo, F. 2011. "An eye-tracking investigation of internet consumers' decision deliberateness," Internet Research, (21:5), pp. 541-561. 
[18] Hyrskykari, A., Ovaska, S., Majaranta, P., Räihä, K. J., and Lehtinen, M. 2008. "Gaze Path Stimulation in Retrospective Think-Aloud," Journal of Eye Movement Research, (2:4), pp. 1-18.

[19] Johnson, B.T., and Eagly, A.H. 1989. "The Effects of Involvement on Persuasion: A Meta-analysis," Psychological Bulletin (106:2), pp. 290-314.

[20] Johnson, E., and Goldstein, D. 2003. "Do Defaults Save Lives?," Science (302), pp. 1338-1339.

[21] Kim, B., Dong, Y., Kim, S., and Lee, K.P. 2007. "Development of Integrated Analysis System and Tool of Perception, Recognition, and Behavior for Web Usability Test: with Emphasis on Eye-tracking, Mouse-tracking, and Retrospective Think Aloud," in Usability and Internationalization. HCI and Culture, pp. 113-121. Springer Berlin Heidelberg.

[22] Lai, Y., and Hui, K. 2006. "Internet Opt-in and Opt-out: Investigating the Roles of Frames, Defaults and Privacy Concerns," in Proceedings of SIGMIS-CPR'06, April 13-15, Claremont, California, USA.

[23] MacInnis, D.J., Moorman, C., and Jaworski, B.J. 1991. "Enhancing and Measuring Consumers' Motivation, Opportunity, and Ability to Process Brand Information from Ads," Journal of Marketing (55:4), pp. 32-53.

[24] Moon, S.Y., Philip, G.C., and Moon, S. 2011. "The Effects of Involvement on ESatisfaction Models," Services Marketing Quarterly (32:4), pp. 332-342.

[25] Monk, A., Wright, P., Haber, J. and Davenport, L. 1993. Improving Your HumanComputer Interface A Practical Technique, New York, Prentice Hall.

[26] Nielsen, J., and Pernice, K. 2009. Eyetracking Web Usability, Fremont, CA: Nielson Norman Group.

[27] Park, D.H., Lee, J., and Han, I. 2007. "The Effect of On-Line Consumer Reviews on Consumer Purchasing Intention: The Moderating Role of Involvement," International Journal of Electronic Commerce (11:4), pp. 125-148.

[28] Pernice, K., and Nielsen, J., 2009. "How to Conduct Eyetracking Studies," http://www.nngroup.com/reports/how-to-conduct-eyetracking-studies/ Accessed: January $28^{\text {th }}, 2015$.

[29] Peter, J.P., and Olsen, J.C. 1987. Consumer Behavior: Marketing Strategy Perspectives, Homewood, Illinois: Irwin.

[30] Samuelson, W., and Zeckhauser, R. 1988. "Status Quo Bias in Decision Making," Journal of Risk and Uncertainty (1:1), pp. 7-59.

[31] Simon, H. 1957. "A Behavioral Model of Rational Choice," in Models of Man, Social and Rational: Mathematical Essays on Rational Human Behavior in a Social Setting. New York: Wiley.

[32] Sivaji, A., Downe, A., Mazlan, M., Soo, S. and Abdullah, A. 2011. "Importance of Incorporating Fundamental Usability with Social and Trust Elements for eCommerce Website," in 2011 International Conference on Business, Engineering and Industrial Applications (ICBEIA), pp. 221-226. IEEE.

[33] Thomsen, C.J., Borgida, E., and Lavine, H. 1995. "The Causes and Consequences of Personal Involvement," in Attitude Strength: Antecedents and Consequences, ed. Petty, R.E. and Krosnick, J.A., pp. 191-214, Mahwah, New Jersey: Erlbaum.

[34] Torres, A., Barry, C., and Hogan, M. 2009. "Opaque Web Practices Among Lowcost Carriers," Journal of Air Transport Management (15), pp. 299-307.

[35] Torres, A.M., Barry, C., and Hogan, M. 2014. "The Identification of Decision Constructs Used in Online Transactional Processes," in $27^{\text {th }}$ Bled eConference, 29 June-3 July, Bled, Slovenia.

[36] Trumbo. C.W. 1999. "Heuristic-Systematic Information Processing and Risk Judgment," Risk Analysis: An International Journal (19:3), pp. 391-400.

[37] Tversky, A., and Kahneman, D. 1981. "The Framing of Decisions and the Psychology of Choices," Science. (211), pp. 453-458. 
[38] Van den Haak, M.J., de Jong, M.D.T., and Schellens, J. 2003. "Retrospective vs. Concurrent Think-aloud Protocols: Testing the Usability of an Online Library Catalogue," Behavior \& Information Technology (22:5), pp. 339-351. 